Published as:

PUSKA M, LASSI LA L, VALLITTU PK, SEPPALA J, MATI NLI NNA J EVALUATI ON OF BI S-GMA/ MMA RESI N ADHESI ON TO SI LI CA-COATED AND SI LANI ZED TITANI UM, J OURNAL OF ADHESI ON SCI ENCE AND TECHNOLOGY, 2009, V. 23(7-8) P. 991-1006

\title{
EVALUATION OF bis-GMA/MMA RESIN ADHESION TO SILICA-COATED AND SILANIZED TITANIUM
}

Mervi Puska ${ }^{1,2}$, Lippo Lassila ${ }^{1}$, Pekka K. Vallittu ${ }^{1}$, Jukka Seppälä2 ${ }^{2}$, and Jukka Matinlinna ${ }^{3,4}$

${ }^{1}$ University of Turku, Institute of Dentistry, Department of Prosthetic Dentistry and Biomaterials Science, FI-20520 Turku, Finland

${ }^{2}$ Helsinki University of Technology, Laboratory of Polymer Technology, FI-02015 Espoo, Finland

${ }^{3}$ Nordic Institute of Dental Materials (NIOM), Haslum, Norway ${ }^{4}$ University of Hong Kong, Faculty of Dentistry, Dental Materials Science, Hong Kong, P.R. China

Corresponding author:

Mervi Puska, Ph.D.,

Helsinki University of Technology,

Laboratory of Polymer Technology,

P.O.Box 6100, FI-02015 HUT (Espoo), Finland.

Tel: +358-9-451 2664,

Fax: +358-9-451 2622,

E-mail: mervi.puska@utu.fi 


\section{ABSTRACT}

The effects of $\mathrm{pH}$ and alcohol solvent type of a silane solution on the bonding of an experimental resin to the silica-coated titanium (Ti) surface were studied. Also, the water sorption of the experimental polymerized resin system employed, i.e. based on a mixture of bis-phenol-A-glycidyl dimethacrylate (bis-GMA) and methyl methacrylate (MMA) prepolymers, was studied. The effect of $\mathrm{pH}$ on 3-methacryloxypropyltrimethoxysilane (MPS) based adhesion promotion was analyzed by determining the shear bond strengths. Two different solvents for diluted MPS were studied, namely in iso-propanol $(\mathrm{i}-\mathrm{PrOH}) / \mathrm{H}_{2} \mathrm{O}$ or ethanol $(\mathrm{EtOH}) / \mathrm{H}_{2} \mathrm{O}$. Bis-GMA/MMA resin stubs were bonded to the Ti surface after tribochemical Rocatec ${ }^{\mathrm{TM}}$ treatment, followed by silanization of the surface with the silane solution. The $\mathrm{pH}$ values were selected as 4.5, 5.0, and 5.5. Then, the bis-GMA/MMA resin stubs were light-cured onto the silica-coated Ti surface ( $n=6 /$ group). Shear bond strengths were determined both before (dry) or after accelerated aging (i.e. thermo-cycling). The shear bond strengths were re-determined after the silane solutions were stored at $+4^{\circ} \mathrm{C}$ for 15 weeks. In dry storage conditions, the shear bond strengths were between 7.5 and 10.6 MPa (ANOVA, p $<0.05$ ), if the Ti surface was silanized with MPS in $i-\mathrm{PrOH} / \mathrm{H}_{2} \mathrm{O}$ solution. In the case of MPS in the $\mathrm{EtOH} / \mathrm{H}_{2} \mathrm{O}$ solution at $\mathrm{pH} 4.5$, the shear bond strength varied between 6.5 and $12.4 \mathrm{MPa}$ in dry storage conditions (ANOVA, $\mathrm{p}<0.05$ ). The silane solution stability evaluation indicated that 15 weeks storage increased the shear bond strength with ca. 1-4 MPa/test group. However, thermocycling reduced the shear bonds in both solvent systems. The weight of the test sample stubs increased by ca. $3.5 \mathrm{wt} \%$ during the water sorption test for $187 \mathrm{~d}$.

Keywords: Silanes, 3-methacryloxypropyltrimethoxysilane, methyl methacrylate, pH, bis -GMA, MMA, Ti, silica-coating 


\section{INTRODUCTION}

Silanes are synthetic hybrid organic-inorganic compounds that are used as coupling agents across organic-inorganic interfaces for bonding dissimilar materials, e.g. paints to metal surfaces [1-3]. In the applications in dentistry and dental technology silanes are widely used as coupling agents for bonding resins to silica-coated metals, ceramics and resin composites [4-7]. When bonding an acrylic resin, the activated alkoxy groups (silanols) in silane molecules react with the metal and the organofunctional group (e.g. vinyl bond in methacrylate group) reacts with the monomeric resin matrix. The use of silanes is based on their molecular structure that contains easily hydrolysable alkoxy groups, such as kinetically favorable methoxy, and organofunctional groups (Figure 1). The silane molecules first must be activated by hydrolyzing the methoxy groups to silanol groups $[4,8]$. When a hydrolyzed silane is applied onto the metal surfaces, the silanol groups will react by forming hydrogen bonds and subsequently covalently bonded siloxane structures on metal surfaces. The organofunctional terminal groups of silane molecules can copolymerize with the monomers of the organic matrix by a radical polymerization reaction [9]. Based on the chemistry described above, silanes are also widely employed in dentistry as coupling agents in practically all resin composite based cements for cementing bridges, metal crowns, onlays, and inlays [4].

Nowadays, there are many commercially available silane products for dental use $[4,10]$. Typically, silane products in dentistry are based on 3-methacryloxypropyltrimethoxy (Figure 2a), a wellknown organofunctional trialkoxysilane. It is normally applied in polar aqueous aliphatic alcohol solutions (e.g. ethanol, iso-propanol) or in ethyl acetate, acetone, and even non-polar alkane solvents (e.g. n-pentane, $n$-hexane) can also been employed; however, the catalysts needed for activation reactions vary [11]. The concentration of 3-methacryloxypropyltrimethoxysilane (MPS) varies usually between 1-5 vol\% in ethanol (EtOH) or iso-propanol (i-PrOH), both diluted with 5- 
$10 \%$ water, but lower silane concentrations are also used [4]. Actually, the low concentration of MPS in solutions is more desirable, because in diluted solutions, the autopolymerization process of silane molecules can be optimized. Moreover, low silane concentrations are known to produce thin siloxane films (with a thickness of ca. $10-50 \mathrm{~nm}$ ) that beneficially can promote the resin-to-metal bond [12].

In dentistry and dental technology, the biomechanical properties of restorative materials should be close to those of the tooth tissues. Dental materials based on bisphenol-A-glycidyl dimethacrylate (i.e. bis-GMA) and triethyleneglycol dimethacrylate (TEGDMA) prepolymers are widely exploited in tooth tissue reconstruction, because the biomechanics of bis-GMA/TEGDMA based polymer systems concurrenting with their clinical handling properties are observed to be relatively good [1315]. Dental resin composite cements containing bis-GMA/TEGDMA as the polymer matrix are often called dual-cured resin systems, where the initiation of polymerization happens either chemically (i.e. peroxide initiated redox polymerization reaction) or blue light-induced (photopolymerization) $[16,17]$. After the initiation step, the polymerization reaction occurs across the vinyl double bonds of methacrylate groups. Typically, these dental resin composites exhibit final double bond conversions of ca. 55-75\% $[18,19]$. As the reaction progresses the double bonds of methacrylate groups of bis-GMA and TEGDMA can also react with the methacrylate group of activated MPS. Thus, the advantages of the utilization of bis-GMA/TEGDMA resin composites are not only the relatively easy redox or light-initiated polymerization mechanism and as a result a highly cross-linked network polymer but also the possibility of the polymer network to be simultaneously covalently bonded to the silanized metal or glass surfaces [4]. 
Some studies have indicated that silane coupling agents play a key role in adhesion promotion. In several papers, the adhesion of methacrylate-based polymers to titanium with the application of MPS has been shown [4, 20-22]. Titanium has been employed as substrate of choice, because it is also potentially used as a dental biomaterial substructure for crowns and bridges, but in particular as implants. In prosthodontics, Ti crowns and bridges, prior to veneering and cementing, are cleaned by a controlled short-term roughening with sand-blasting and silica-coated by tribochemical Rocatec $^{\mathrm{TM}}$ (3M ESPE) or $\operatorname{CoJet}^{\mathrm{TM}}$ system before silanization $[4,6,23]$. The roughening method is based on an abrasive blasting with special silica-modified aluminium oxide sand particles that provides both micromechanical retention and promotes chemical adhesion and thus improves the bond strength effectively [21].

A well-known drawback of dental materials based on bis-GMA/TEGDMA is their tendency to absorb water (i.e. water uptake) in the oral environment, as well as the (always existing) incomplete conversion of double bonds. In fact, it has been shown that the cured polymer network can contain up to $6 \mathrm{wt} \%$ residual uncured monomers [24]. The release of unreacted monomers which are usually mainly methyl methacrylate (MMA) from resin composites may promote allergic reactions in some patients [25]. The water uptake determination of the experimental materials used in oral environment in conjunction with the shear bond strength measurements is normally carried out. Thus, before testing the shear bond strengths, the dental materials are also regularly subjected to alternating thermal stress (i.e. thermo-cycling), in order to try to simulate the in vivo circumstances and usually testing after dry storage is carried out for comparison [26]. In thermo-cycling, the alternating temperatures are typically $+5^{\circ} \mathrm{C}$ for cold exposure and $+55^{\circ} \mathrm{C}$ for hot exposure. The specimens exposed to thermal stress have mostly lower shear bond strength values compared to those not subjected to thermal stress (i.e. kept in dry storage conditions). It can be summarized that 
the clinical applications require a good knowledge of various biomechanical properties of the dental materials, such as the bond strength and water uptake in simulated oral environment.

In this study, surface silanization with MPS was studied in order to determine the durability of an experimental resin bonded to Ti substrate. We wanted to understand more about the effects of (a) $\mathrm{pH}$ of the solution, (b) the aliphatic alcohol type in the solvent, and finally, (c) the hydrolysis time on the bond strength. These aspects have not been widely reported in the dental materials literature. According to our hypothesis, solvent and $\mathrm{pH}$ can affect the compatibility of the silane molecule in the adhesion promotion system and hence enhance it or, in the case of null hypothesis, rather deteriorate the bond strength. The hypothesis advocates that there can be significant differences in the shear bond strength values. In this study, experimental silane solutions, with MPS concentrations of $0.01 \mathrm{vol} \%$, were prepared in $i-\mathrm{PrOH} / \mathrm{H}_{2} \mathrm{O}$ or $\mathrm{EtOH} / \mathrm{H}_{2} \mathrm{O}$ solutions, the $\mathrm{pH}$ of which was adjusted to $4.5,5.0$, or 5.5. It has been shown that water sorption affects the long-term stability of dental polymers [27]. Therefore, the water sorption was also determined for the experimental resin employed in the shear bond strength investigation in this paper. It was expected that there will be high sorption tendency for water for the experimental resin system.

\section{MATERIALS AND METHODS}

\subsection{Preparation of Experimental Resin System}

The materials used in this study are listed in Table 1. In addition, Figure 2 shows the molecular structures of compounds used in the experimental resin and silane. The laboratory-made experimental resin contained $78.43 \mathrm{wt} \%$ bis-GMA and $19.61 \mathrm{wt} \%$ methyl methacrylate (MMA). Thereafter, $0.98 \mathrm{wt} \%$ of initiator of photo-polymerisation (i.e. camphorquinone) and $0.98 \mathrm{wt} \%$ of activator ( $N, N$-dimethylaminoethyl methacrylate, DMAEMA) were added to the mixture of bis- 
GMA and MMA. The mixture of experimental resin (Table 1) was prepared within 15-30 min and packed in light protected polyethylene syringes. Thereafter, the resin was stored at $+4^{\circ} \mathrm{C}$ before preparing test specimens.

\subsection{Preparation of Experimental Trialkoxysilane Solutions and Their Stability Study}

Two experimental $0.01 \mathrm{vol} \%$ solutions of MPS were prepared, in which accurate amounts of MPS were dissolved in a solvent mixture of $95 \mathrm{vol} \% / 5 \mathrm{vol} \% \mathrm{i}$-PrOH and de-ionized water (Milli-RO Plus 30 de-ionized water, with a resistivity of $18 \mathrm{M} \Omega \mathrm{cm}$, Millipore) or $95 \mathrm{vol} \% / 5 \mathrm{vol} \% \mathrm{EtOH} /$ deionized water. 3-methacryloxypropyltrimethoxysilane (MPS) was purchased from Sigma-Aldrich Chemie GmbH (Steinheim, Germany, Lot. S01603-022, purity 98\%, unredistilled). Three silane solutions with different $\mathrm{pH}$ values were prepared in both alcohols, in which the $\mathrm{pH}$ was adjusted to $4.5,5.0$, or 5.5 with $1 \mathrm{M}$ acetic acid (Merck, Darmstadt, Germany). Thereafter, the carefully sealed silane solutions were allowed to hydrolyze at room temperature for $1 \mathrm{~h}$, before they were employed [10, 11, 21]. These silane solutions were also subjected to the stability test, which was performed by storing the silane solutions after the silanizations carefully sealed in dark at $+4^{\circ} \mathrm{C}$ prior to the bonding procedure for 15 weeks.

\subsection{Grit-Blasting of the Ti substrate}

Titanium used in the studies was commercially pure grade 2 (Permascand Ltd., Ljungaverk, Sweden, Lot. ASTM B26589). Titanium was cut to ca. $25 \mathrm{~mm}$ x $55 \mathrm{~mm}$ x $1 \mathrm{~mm}$ planar slides $(\mathrm{N}=48)$. The surface was finished and polished with silicon carbide (SiC) paper (1200 grit; $0.15 \mu \mathrm{m}$ particles). Then, the slides were cleaned for $10 \mathrm{~min}$ in an ultrasonic bath (Quantrex $90 \mathrm{WT}, \mathrm{L} \& \mathrm{R}$ Manufacturing, Inc., Kearny, NJ, USA) and finally rinsed with ethanol and acetone, in order to remove any grease and other impurities. A part with an area of approximately $10 \mathrm{~mm}$ x $55 \mathrm{~mm}$ of 


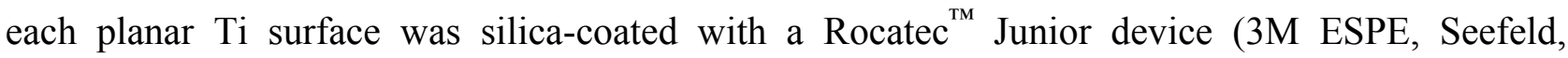
Germany), where the sand employed in Rocatec ${ }^{\mathrm{TM}}$ Plus (3M ESPE, Seefeld, Germany), was 110 $\mu \mathrm{m}$ aluminum trioxide $\left(\mathrm{Al}_{2} \mathrm{O}_{3}\right)$ abrasion particles with uniform silica $\left(\mathrm{SiO}_{2}\right)$ coating. Only the above-mentioned area was needed for the resin stubs to be light-polymerized onto surface conditioned (silicatized) and silanized Ti substrates. The silicatization was carried out using a pressure of $280 \mathrm{kPa}$, for a period of $10 \mathrm{~s}$ per ca. $1 \mathrm{~cm}^{2}$ of the total area to be silicatized, from a perpendicular distance of $10 \mathrm{~mm}$. Prior to silanization, the Ti slides were air-blasted with oil-free compressed air and kept in a desiccator.

\subsection{Bonding, Shear Bond Strength Testing, and Silane Solution Stability Evaluation}

Table 2 shows the classification of test groups for which the shear bond strengths of resin stubs to Ti were measured. Before the resin was bonded, the Ti slides were silanized at room temperature in the following manner: 2-3 drops of silane solution were brushed on the substrate (one coat of silane) and allowed to react for 5 min (i.e. visually dry on the surface). Experimental resin was applied in polyethylene cylindrical molds as resin stubs $(\mathrm{n}=6)$ with a diameter of $3.6 \mathrm{~mm}$ and height of $10 \mathrm{~mm}$ onto the surface-treated Ti slides. Figure 3 presents the test setup for measuring the shear bond strengths. The resin stubs were light-cured (Optolux 501, SDS Kerr, Danbury, CT, USA) for $40 \mathrm{~s}$ at an average light intensity of $800 \mathrm{~mW} \mathrm{~cm}^{-2}$. For completing the polymerization, the specimens were also in a light-curing oven unit (Vision Beta, 3M ESPE GmbH, Seefeld, Germany) for $15 \mathrm{~min}$ in a vacuum. This is a custom procedure carried out at dental laboratories. The molds were then removed carefully by pressing at the same time the cured resin stub with a hand-piece instrument. The shear bond test was conducted for one half of the specimens after a dry storage in a desiccator at room temperature, i.e. in 'dry storage conditions' (labeled "Dry"). The other half (labeled "Tc") were subjected to thermal stress for 6000 cycles at temperatures alternating between 
$+5^{\circ} \mathrm{C}$ and $+55^{\circ} \mathrm{C}$ with an exposure time of $30 \mathrm{~s}$ and a transfer time of $2 \mathrm{~s}$. In addition, after a storage period of silane solutions in the dark at $+4^{\circ} \mathrm{C}$ for 15 weeks, the shear bond strengths were measured once again using the same test setup as described above, to carry out the stability investigation. The silane solutions were allowed to stabilize to room temperature before use. Shear bond strength were measured with a universal material testing machine (LRX, Lloyd Instruments Ltd., Farham, UK), using a crosshead speed of $1.0 \mathrm{~mm} / \mathrm{min}$. This machine was used according to the recommendation stated in ISO 10477 [28]. The shear bond strength was calculated using NEXYGEN 2.0 software (Nexygen, Lloyd Instruments Ltd., Fareham, UK). The following formula was used to calculate the shear bond strength $(\sigma)$ :

$$
\sigma=\mathrm{F} / \mathrm{A}
$$

where $\mathrm{F}$ is the applied load at the failure of the bonds during the shear test and $\mathrm{A}$ is the crosssectional area of resin stubs.

\subsection{Water Sorption Study}

The water sorption test was based on ISO 3696:1987 (E) and carried out accordingly [29]. The test specimens $(\mathrm{N}=10)$ for water sorption study were stored in contact with $15 \mathrm{ml}$ of de-ionized Milli-Q water (grade 2) at $+37^{\circ} \mathrm{C}$. in sealed polypropylene flasks for the following time periods: $0,4,5,6$, $7,11,15,22,36,40,99$ and 187 days. The weight increase was calculated as weight percentage (wt $\%)$ of the mass of the test specimen.

\subsection{Statistical Analysis}

The mean values for shear bond strength data were analyzed in order to determine the statistical significance of the results using ANOVA. The statistical analysis was performed using SPSS (Statistical Package for Social Science, SPSS inc., Chicago, IL, USA) software for Windows. The dependent variable (shear bond strength) was discussed in terms of the independent variables (i.e. 
the $\mathrm{pH}$ and hydrolysis time of silane, alcohol type, and submission of specimens to thermal stress), followed by post-hoc test.

\section{RESULTS}

ANOVA revealed that the independent variables (see above) had some effect on shear bond strength. However, one of the independent variables, i.e. subjecting the specimens to thermal stress, had the most significant effect. In dry storage conditions, the shear bond strengths varied between 7.6 and 10.9 MPa (ANOVA, p < 0.05), when the Ti-substrate was silanized using MPS in $i$ $\mathrm{PrOH} / \mathrm{H}_{2} \mathrm{O}$ solution. The highest shear bond strength was obtained $(10.9 \mathrm{MPa})$ at $\mathrm{pH} 4.5$ in $i-$ $\mathrm{PrOH} / \mathrm{H}_{2} \mathrm{O}$ solution, whereas the lowest value was $6.5 \mathrm{MPa}$ at $\mathrm{pH} 4.5$ obtained using MPS in $\mathrm{EtOH} / \mathrm{H}_{2} \mathrm{O}$ solution. After thermo-cycling, the shear bond strengths of all test groups were reduced in both alcohol/water solution types and at all three $\mathrm{pH}$ levels. In the case of $1 \mathrm{~h}$ hydrolysis for the silane solution and after subjecting to thermal stress, the shear bond strength was least reduced at $\mathrm{pH} 4.5$ from 6.5 MPa to 6.3 MPa (ANOVA, $\mathrm{p}<0.05$ ), when Ti-substrate was silanized with MPS in $\mathrm{EtOH} / \mathrm{H}_{2} \mathrm{O}$. In the case of MPS in $\mathrm{i}-\mathrm{PrOH} / \mathrm{H}_{2} \mathrm{O}$ solution, the shear bond strength least reduced at pH 5.5 (from 7.5 MPa to 5.8 MPa).

Figures 4 shows the results of shear bond strength measurements before and after the stability investigation of different silane solutions. For silane solutions aged for 15 weeks, the shear bond strengths were observed to be numerically higher in both alcohol/water solutions and at each $\mathrm{pH}$ level tested. The highest shear bond strength was achieved at $\mathrm{pH} 4.5$ and the lowest at $\mathrm{pH} 5.5$. In the case of MPS in EtOH/ $\mathrm{H}_{2} \mathrm{O}$ solution, the highest shear bond strength was $12.4 \mathrm{MPa}$ in dry conditions (dry storage) at $\mathrm{pH} 4.5$. In the case of MPS in $i-\mathrm{PrOH} / \mathrm{H}_{2} \mathrm{O}$ solution at $\mathrm{pH} 5.5$ after dry storage, the shear bond strength was the lowest i.e. 8.5 MPa, (ANOVA, p < 0.05). Thermo-cycling 
reduced also the shear bond strengths, when 15 weeks old silane solutions were employed. However, the shear bond strengths did not reduce significantly at $\mathrm{pH} 4.5$ in the case of MPS in $i$ $\mathrm{PrOH} / \mathrm{H}_{2} \mathrm{O}$ solution.

Figure 5 shows the weight curve of water sorption test. After $7 \mathrm{~d}$ immersion time, the water sorption first decreased somewhat the weight of specimens (ca. $0.4 \mathrm{wt} \%$ ). After $11 \mathrm{~d}$ immersion time, the weight of specimens increased by $c a .1 .7 \mathrm{wt} \%$. The saturation point of water sorption was achieved in $22 \mathrm{~d}$, after which the weight of specimens remained constant. At the end of water uptake capacity measurement, the weight of specimens had increased approximately by $3.5 \mathrm{wt} \%$.

\section{DISCUSSION}

Based on this study, the new information obtained on the adhesion promotion with MPS solutions should improves understanding and application of silane-aided bonding concept. In addition, the ageing time study of experimental silane solutions has some scientific interest, since no inhibitors were used in the experimental solutions to inhibit the hydrolysis of MPS. Previously, it had been reported that the metal cleaning procedure as well as the concentration and $\mathrm{pH}$ of silane depend on the formation of silane films i.e. silane deposition time and speed onto metals, thus affecting substantially the adhesion promotion performance $[3,11]$. Therefore, in this study, the effects of $\mathrm{pH}$ and the aliphatic alcohol solvent system used for the bonding capability of the silane molecule between bis-GMA/MMA resin system and silica-coated Ti surface were evaluated. Moreover, the effects of subjecting the experimental resin stubs to thermal stress (artificial aging) and the stability of silane solution after 15 weeks aging were studied based on the fact that dilute MPS solutions are known to retain for a long period their coupling properties [30]. 15 weeks correspond to a clinically relevant time period for checking the stability of experimental silane solutions. There has also been 
continued interest and demand in developing experimental silane-based adhesion promoters for applications in dentistry and in general in adhesion technology.

The tested silane of interest and choice was MPS (0.01 vol\%) in iso-propanol $(i-\mathrm{PrOH}) / \mathrm{H}_{2} \mathrm{O}$ or ethanol $(\mathrm{EtOH}) / \mathrm{H}_{2} \mathrm{O}$ solutions, in which $\mathrm{pH}$ had been adjusted to 4.5, 5.0, or 5.5. For one half of the specimens, the shear bond test was conducted after storage in dry conditions at room temperature for $2 \mathrm{~h}$, whereas the other half were subjected to thermal stress (thermo-cycling) to simulate the aging process in oral environment. The other tested materials, Ti and bis-GMA/MMA resin, were selected because of their broad utilization not only in dentistry but also in some medical devices [31]. Actually, Ti works excellently as a biomaterial and its surface is easy to modify with silanes, in principle, without [22] or with silica-coating, because of the original and utmost thin oxide layer on its outermost surface [10]. However, silicatization is often recommended prior to silanization in stead of a direct silanization [4, 20,21]. Although, MPS has shown some preliminary signs of osteoconductive properties but still can be a relevant silane of choice in biomaterials research [32].

In dental laboratories, tribochemical Rocatec ${ }^{\mathrm{TM}}(3 \mathrm{M} / \mathrm{ESPE})$ system as a custom pretreatment method is widely employed for metals, amalgams and ceramics $[6,23]$. In this study, the Rocatec ${ }^{\mathrm{TM}}$ treatment was supposed to produce a relatively uniform and visually rough $\left(\mathrm{Al}_{2} \mathrm{O}_{3}+\mathrm{SiO}_{2}\right)$ outer layer on Ti surface. Figure 3 shows the test setup for measuring the shear bond strength. In terms of tribochemical Rocatec ${ }^{\mathrm{TM}}$ treatment, the sandblasting of $\mathrm{Ti}$ plates created a microretentive $\mathrm{Ti}$ surface. This means that the adhesion of the studied resin system will increase, as Matinlinna and co-workers had previously reported $[21,22]$. Therefore, in this study, the failure of the bonds during the shear test was also cohesive in the resin for all specimens. Before the application of the experimental resin onto $\mathrm{Ti}$ substrate, the Rocatec ${ }^{\mathrm{TM}}$ treated surface was silanized using four 
different silane solutions ( $c f$. types 1-4, Table 2) with controlled $\mathrm{pH}$ levels. The $\mathrm{pH}$ levels used were based on of the most often $\mathrm{pH}$ values used in the literature with MPS. Figure 1 shows two key reactions that are supposed to occur in the silane solution during its hydrolysis $[1,2]$. In the first step, the alkoxy groups are hydrolysed resulting in intermediate silanol species. The reaction is relatively fast for the kinetically labile methoxy groups. In the second step, the silanols condense to form hydrogen bonds and siloxane bonds (-Si-O-Si-) to connect the monomer resin phase chemically to the conditioned Ti substrate [4]. In fact, it has been proposed that the $\mathrm{pH}$ level may control both the hydrolysis and condensation reactions in dilute silane solutions [33]. In addition, these two primary reactions can also be influenced by other solution variables such as catalyst, silane concentration, and temperature but this discussion is beyond the scope of this study and the reader should refer to [34, 35]. In fact, the hydrolysis of MPS does not require addition of any acids, because the de-ionized water is slightly acidic, i.e. its $\mathrm{pH}$ is between 6 and 7. If acid will be added to the diluted MPS solutions, the kinetically controlled hydrolysis reaction will be faster and more effective. Therefore, after 15 weeks, the hydrolysis of MPS would most likely have occurred in pure the de-ionized water. This will be studied further by the authors.

The solvent might affect the siloxane film formation and hence the adhesion promotion. Therefore, two aliphatic, "typical" alcohols were employed for comparing the obtained shear bond strengths at three $\mathrm{pH}$ values in two hydrolysis and ageing times. However, methanol as the simplest aliphatic alcohol was excluded from the test setup due to its obvious hazards (toxicity). According to the shear bond strength results, $i-\mathrm{PrOH}$ seems to be a more suitable solvent in conjunction with water for the MPS solution, in particular, if the hydrolysis time is relatively short. Some reasons for this presumption are based on very high surface energy, i.e. lower surface tension on the $\mathrm{Al}_{2} \mathrm{O}_{3}+\mathrm{SiO}_{2}$ coated Ti surface, resulting a better wettability and slightly slower evaporation of $i$-PrOH (bp. 82 
${ }^{\circ} \mathrm{C}$, STP) compared to ethanol (bp. $79{ }^{\circ} \mathrm{C}$, STP). Thus, the ratio between surface tension and viscosity has been reported to be higher for $\mathrm{EtOH}$ than $i$-PrOH [36]. Therefore, a binary mixture of $i-\mathrm{PrOH}$ and water might form a siloxane film more prone to promote adhesion on the outermost surface of the metal substrate. This effect should be investigated more in the future. This research also confirmed that $1 \mathrm{~h}$ time period is long enough for activating the inorganic groups in MPS molecule in $\mathrm{i}-\mathrm{PrOH} / \mathrm{H}_{2} \mathrm{O}$.

In dry storage conditions, the highest shear bond strength obtained was $10.6 \mathrm{MPa}$, comparable to the value obtained with MPS in $\mathrm{EtOH} / \mathrm{H}_{2} \mathrm{O}$, where the highest mean shear bond strength was 8.2 MPa (ANOVA, $\mathrm{p}<0.05$ ). In addition, the lower $\mathrm{pH}$ value seems to active a rapid hydrolysis reaction of MPS in $i-\mathrm{PrOH} / \mathrm{H}_{2} \mathrm{O}$ solution. When silanization was carried out using 15 weeks old MPS prepared in $i-\mathrm{PrOH} / \mathrm{H}_{2} \mathrm{O}$ at $\mathrm{pH} 4.5$, the shear bond strengths obtained were slightly higher, even after thermo-cycling. However, if the stability test storage time would have been longer, the bonding capability of MPS might have decreased. Namely, based on the visual observations, MPS in $i-\mathrm{PrOH} / \mathrm{H}_{2} \mathrm{O}$ showed some signs of ageing, i.e. a tiny $\mathrm{SiO}_{2}$-gel formation. Such gel-like $\mathrm{Si}$ makes obviously the coupling properties inferior. For activating the alkoxy groups of MPS in EtOH/ $\mathrm{H}_{2} \mathrm{O}$, $1 \mathrm{~h}$ hydrolysis time is usually enough $[5,10,20]$. Interestingly, the highest shear bond strength (12.4 MPa) in EtOH/ $\mathrm{H}_{2} \mathrm{O}$ was obtained at $\mathrm{pH} 4.5$ using a silane solution which had a hydrolysis period of 15 weeks. The hydrolysis in $\mathrm{EtOH} / \mathrm{H}_{2} \mathrm{O}$ seems to occur at a slower rate by hindering the very rapid condensation of activated silane, which apparently occurs due to the presence of appropriate catalyst [19-21]. Therefore, the reaction activity of MPS in EtOH/ $\mathrm{H}_{2} \mathrm{O}$ solution may be more vital after 15 weeks hydrolysis. This behaviour merits further studies in the future. 
It has been shown that both the shear bond strength and tensile bond strength depend highly on the materials and the geometry of the test arrangement [37]. The strength of a material and the strength of the union of dissimilar materials are object to a great deal of work reported in dental materials research. Moreover, mechanical testing for the strength of a material is a substantially more complicated issue than it appears at first sight. The definition is easy enough: stress at failure but the ultimate question remains: does the testing simulate enough the real clinical conditions in the oral environment [38]? It can be summarized that in dental materials science, the shear bond strength is a widely used parameters for estimating how strong the union between dissimilar dental materials would be. However, in this study, the number of specimens in a single test-group was relatively low, i.e. six. Nevertheless such numbers are statistically relevant and have, in principle, successfully been used in dental materials research and testing previously [20,39].

The silanization was based on an aqueous silane solution at controlled $\mathrm{pH}$. Typically, the $\mathrm{pH}$ range between 4.5 and 5.5 is commonly used for silane solutions based on published literature $[1,4,10$, $11,20]$. In addition, some investigations have indicated that the $\mathrm{pH}$ of an organosilane coupling agent solution can influence the nature of the various reactions which occur in solutions [35]. In the analysis of data between the groups, there were many independent variables (i.e. the $\mathrm{pH}$ and hydrolysis time of silane, alcohol type, and subjecting to thermal stress) as well as their interactions that had some effect on the shear bond strengths. However, when subjected to thermal stress caused the most significant difference between the shear bond strengths of various groups. However, the results of this study indicated that the hydrolysis of MPS occured readily in the solution containing iso-propanol. According to the results of this study, there was not found significant dependence between $\mathrm{pH}$ in the range of 4.5-5.5 in comparison for the both solvent systems. Nevertheless, silane solutions with the lowest $\mathrm{pH}$ value (4.5) seemed to produce, on average, slightly higher bond 
strengths compared to the strength values obtained with silane solutions with higher $\mathrm{pH}$ values, in the case of MPS dissolved in $i-\mathrm{PrOH} / \mathrm{H}_{2} \mathrm{O}$. The tested $\mathrm{pH}$ range was selected based on literature [1, $4,5]$ and in the future studies we may widen this range. The polarity of tested alcohol solvents did not differ enough, polarity index for $\mathrm{EtOH}$ is 5.2 and for $i-\mathrm{PrOH} 4.0$ [40]. Therefore, for continuing these studies, the effect of $\mathrm{pH}$ in lower and higher value would be scientifically interesting to be evaluated even in other type of alcohols, e.g. 1-butanol or a highly polar, electronegative 2,2,2trifluoroethanol.

Figure 4 presents the results of thermo-cycling and silane stability (storage) tests. As expected, thermo-cycling produced lower mean shear bond strengths values with all silane solutions. According to the literature, thermo-cycling is generally known to decrease the shear bond strengths $[10,20-22,25]$. However, after 15 weeks of ageing, the shear bond strengths were found to be relatively and sufficiently high, if MPS in $i-\mathrm{PrOH} / \mathrm{H}_{2} \mathrm{O}$ solution, adjusted at the lowest used $\mathrm{pH}$ value, was employed. Interestingly, the shear bond strengths did not decrease significantly after exposure to thermal stress. The relatively rapid hydrolysis of MPS in $i-\mathrm{PrOH} / \mathrm{H}_{2} \mathrm{O}$ solution can be concluded to remain stabile, if the silane solution is stored carefully in sealed flasks in the dark at $+4^{\circ} \mathrm{C}$ prior to the bonding procedure. In addition, the thermal stress might, to some extent, increase the condensation reaction of this kind of MPS solution. However, this needs to be investigated more precisely to obtain further evidence of this presumption. In the case of $\mathrm{EtOH}$, it was recognised that the age of the silane solution played an important role and had influence on shear bond strength. After subjecting to thermal stress, the highest shear bond strength was obtained at the highest $\mathrm{pH}$ value in $\mathrm{EtOH} / \mathrm{H}_{2} \mathrm{O}$ solution. According to the results of shear bond strengths, the most suitable $\mathrm{pH}$ value for activating MPS in $\mathrm{EtOH} / \mathrm{H}_{2} \mathrm{O}$ solution is 5.5, whereas the activation in $i$ $\mathrm{PrOH} /$ water solution was found to be most effective at $\mathrm{pH} 4.5$. 
Water sorption of polymer plays an important role in long-term stability of dental appliances in an aqueous environment [27]. Therefore, it was also relevant to study the diffusion of water molecules into the experimental polymer used in this research. According to the results of water sorption, the weight of specimens first decreased by $0.25 \mathrm{wt} \%$ in 7 days. The weight loss most probably indicates unreacted residual monomers in the polymerized bis-GMA/MMA resin were released (this was not detected by chemical analysis, though). In the course of time, the water sorption then stabilized within $22 \mathrm{~d}$, when the weight of specimens had increased by ca. $3.5 \%$. After $22 \mathrm{~d}$, the amount of water did not increase during the subsequent period of $165 \mathrm{~d}$. According to the results of this water sorption and bond durability study, MPS in either $\mathrm{EtOH} / \mathrm{H}_{2} \mathrm{O}$ or $\mathrm{i}-\mathrm{PrOH} / \mathrm{H}_{2} \mathrm{O}$ solution, is a suitable promoter in the adhesion of bis-GMA/MMA resin to silica-coated Ti substrate, when the $\mathrm{pH}$ of silane solution is between 4.5 and 5.5. Moreover, the water sorption of the experimental dental resin was relatively low.

\section{CONCLUSIONS}

Within the limited scope of this pilot study, the following conclusions can be drawn:

(1) The $\mathrm{pH}$ range of 4.5 to 5.5 is relevant to activate MPS in the studied two solvent systems, based on $\mathrm{EtOH}$ and $i-\mathrm{PrOH}$, and with a final hydrolysis time of 15 weeks.

(2) In the case of $i-\mathrm{PrOH} / \mathrm{H}_{2} \mathrm{O}$ at $\mathrm{pH} 4.5$, the highest adhesion promotion capacity for MPS was

obtained within $1 \mathrm{~h}$. The thermal stress (i.e. aging by thermo-cycling) did not reduce the shear bond strength values significantly, i.e. from 10.2 MPa to 7.7 MPa (ANOVA, $\mathrm{p}<0.05$ ). In addition, if 15 weeks old silane solutions were used for adhesion promotion, the shear bond strength values did not decrease dramatically, i.e. $\sim 1-4 \mathrm{MPa} /$ test group. 
(3) The water uptake of the experimental bis-GMA/MMA-based non-filled polymer was ca. 3.5 wt $\%$ in 187 days.

\section{ACKNOWLEDGEMENTS}

The research was conducted as a part of the Bio- and Nanopolymers Research Group activity of the Center of Excellence (CoE), which is jointly funded by the Academy of Finland and TEKES (Finnish Funding Agency for Technology and Innovation). It was also part of the NIOM (Nordic Institute of Dental Materials, Oslo, Norway) Biomaterials Network in the Nordic Countries. Ms. Hanna Hark, BSc. (University of Turku) and Mr. Torbjørn Knarvang, B.Sc. (Nordic Institute of Dental Materials, NIOM) are thanked for their skilful technical assistance.

\section{REFERENCES}

[1] E. Plueddemann, J. Adhesion 2, 184 (1970).

[2] E. Plueddemann and G. Stark, Mod. Plast. 54, 102 (1977).

[3] T. Child and W. van Ooij, Trans. Inst. Metal Finish. 77, 64 (1999).

[4] J. Matinlinna, L. Lassila, M. Özcan, A. Yli-Urpo, and P. Vallittu, Int. J. Prosthodont. 17, 155 (2004).

[5] T. Hooshmand, R. Daw, R. van Noort, and R. Short, Dental Mater. 17, 1 (2001).

[6] M. Özcan, J. Prosthet. Dentistry $\underline{87}, 469$ (2002).

[7] J.P. Matinlinna, M. Ozcan, L.P.J. Lassila and P.K. Vallittu, Applications of Trialkoxysilanes in Dental Biomaterials: A Review, in Silanes and Other Coupling Agents, Vol. 4, K.L. Mittal (ed.), pp. 199-215, VSP/Brill, Leiden, The Netherlands (2007)

[8] E. Plueddemann, H. Clark, L. Nelson, and K. Hoffman, Mod. Plast. 39, 135 (1962). 
[9] J. Marsden, in: Handbook of Adhesives, I. Skeist (Ed.), pp. 536-548. Van Nostrand Reinhold, New York (1990).

[10] J. Matinlinna, L. Lassila, and P. Vallittu, J. Dentistry 34, 721 (2006).

[11] T. Chen and G. Brauer, J. Dental Res. 61, 1439 (1982).

[12] W. van Ooij, D. Zhu, G. Prasad, S. Jayaseelan, Y. Fu, and N. Teredesai, Surface Eng. 16, 386 (2000).

[13] N. Lin, P. Drzal, and S. Lin-Gibson, Dental Mater. 23, 1211 (2007).

[14] E. Asmussen and A. Peutzfeldt, Dental Mater. 14, 51 (1998).

[15] Y. Finer and J. Santerre, J. Biomed. Mater. Res. $\underline{81 \mathrm{~A}}, 75$ (2007).

[16] Y. Chen, J. Ferracane, and S. Prahl, Dental Mater. 23, 655 (2007).

[17] W. Schroeder and C. Vallo, Dental Mater. 23, 1313 (2007).

[18] B. Kalipcilar, L. Karaagaclioglu, and U. Hasanreisoglu, J. Oral Rehabil. 18, 399 (1991).

[19] E. Viljanen, M. Skrifvars, and P. Vallittu, J. Appl. Polym. Sci. $\underline{93}, 1908$ (2004).

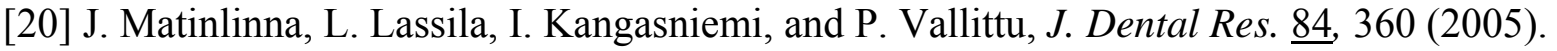

[21] J. Matinlinna, L. Lassila, I. Kangasniemi, A. Yli-Urpo, and P. Vallittu, Dental Mater. 21, 287 $(2005)$

[22] J. Matinlinna, M. Özcan, L. Lassila, and P. Vallittu, Dental Mater. 20, 804 (2004).

[23] M. Özcan, J. Prosthodont. 15, 47 (2006).

[24] M. Taira, A. Khan, K. Ohmoto, N. Satou, H. Shintani, K. Wakasa, and M. Yamaki, J. Mater. Sci. Lett. 13, 1229 (1994).

[25] H. Schweikl, G. Spagnuolo, and G. Schmalz, J. Dental Res. 포, 870 (2006).

[26] M. Gale and B. Darvell, J. Dentistry 27, 89 (1999).

[27] V. Miettinen, K. Narva, and P. Vallittu, Biomaterials 20, 1187 (1999).

[28] ISO 10477:2004, Dentistry - Polymer-based crown and bridge materials 
[29] ISO 3696:1987 (E), Water for analytical laboratory use - Specification and test methods

[30] T. Hooshmand, R. van Noort, and A. Keshwad, Dental Mater. 20, 635 (2004).

[31] E. Erbe, T. Clineff, and G. Gualtieri, Eur. Spine J. 10, S147 (2001).

[32] S. Shinzato, T. Nakamura, T. Kokubo, and Y. Kitamura, J. Biomed. Mater. Res. 55, 277 (2001).

[33] P. Erickson and E. Plueddemann, Historical background of the interface: Studies and theories, in Composite Materials, Vol. 6, E. Plueddemann (ed.), pp. 1-29, Academic Press, New York, USA (1974).

[34] M.-L. Abel, R. Allington, R. Digby, N. Porritt, S. Shaw, and J. Watts, Int. J. Adhesion Adhesives 26, 2 (2006).

[35] G. Tesoro and Y. Wu, J. Adhesion Sci. Technol. ㅁ, 771 (1991).

[36] A. Han, G. Mondin, N. Hegelbach, N. De Rooij, and U. Staufer, J. Colloid Interface Sci. 293, $151(2006)$.

[37] R. van Noort, S. Noroozi, I. Howard, and G. Cardew , J. Dentistry 17, 61 (1989).

[38] B. Darvell, J. Mater. Sci. 25, 757 (1990).

[39] M. Dündar, M. Özcan, B. Gokce, E. Comlekoglu, F. Leite, and L. Valandro, Dental Mater. 23, 630 (2007).

[40] P. Di Martino, R. Censi, L. Malaj, D. Capsoni, V. Massarotti, and S. Martelli, Cryst. Res. Technol. $\underline{42}, 800$ (2007). 
(A) HYDROLYSIS<smiles>C=C(C)C(=O)OCCC[Si](OC)(OC)OC</smiles>

(B) CONDENSATION<smiles>C=C(C)C(=O)OCCC[Si](O)(O)O</smiles><smiles>[CH][CH2]</smiles>
Inorganic groups react
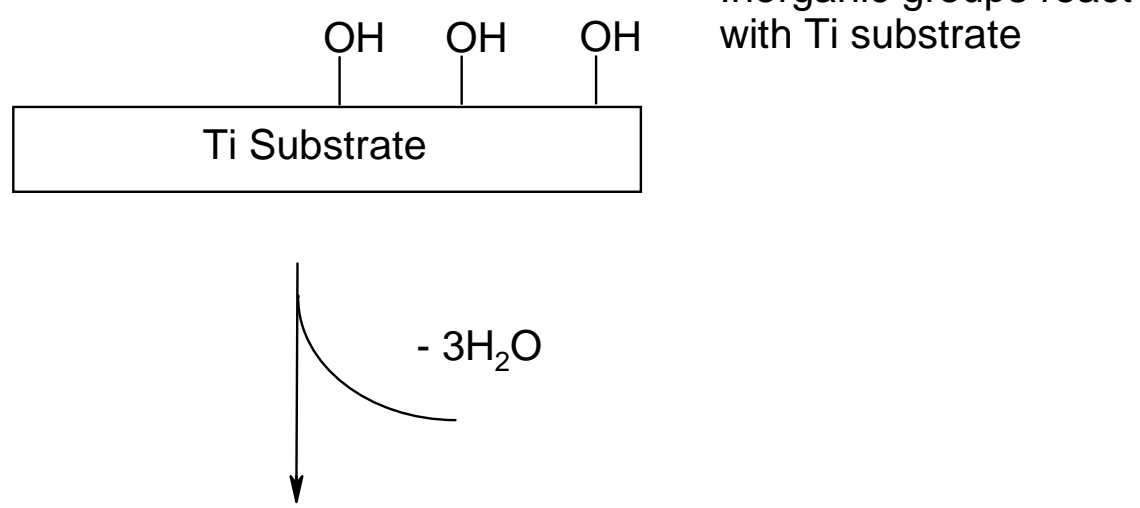

Organic group reacts with dental resin

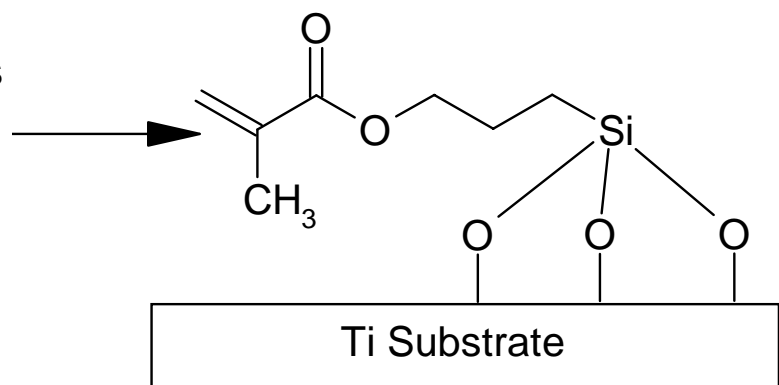

FIGURE 1. The illustration above shows (A) the hydrolysis reaction of MPS that activates the inorganic groups of the silane molecule and (B) the condensation reaction by which silane is adsorbed onto the surface of Ti substrate. 
<smiles>C=C(C)C(=O)OCCC[Si](OC)(OC)OC</smiles>

(a)<smiles>C=C(C)C(=O)OCCN(C)C</smiles>

(b)<smiles>C=C(C)C(=O)OC</smiles>

(c)<smiles>C=C(C)C(=O)OCC(O)COc1ccc(C(C)(C)c2ccc(OCC(O)COC(=O)C(=C)C)cc2)cc1</smiles>

(d)

FIGURE 2. The molecular structures of compounds containing methacrylate group used in the experiments: (a) methacryloxypropyltrimethoxysilane, MPS, (b) $N, N$-dimethylaminoethyl methacrylate, DMAEMA, dimethacrylate, bis-GMA.

(c) methyl methacrylate, MMA, and (d) bisphenol-A-glycidyl 


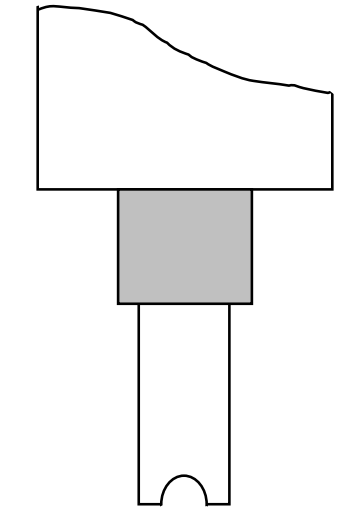

$\mathbf{F}$

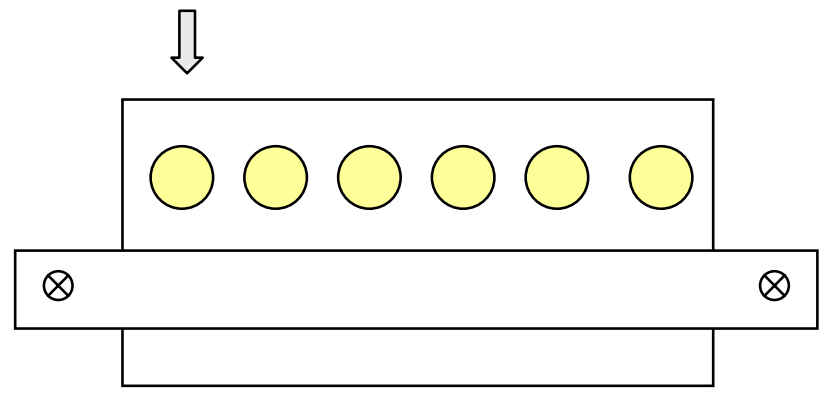

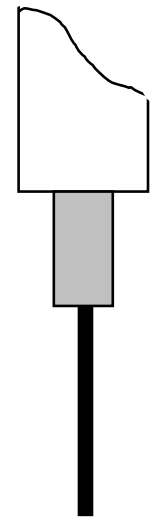

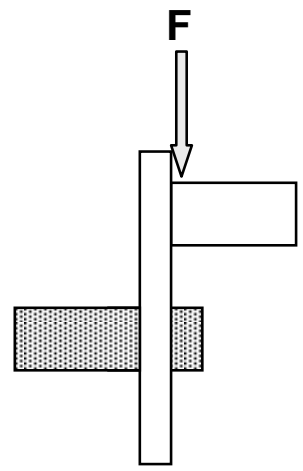

FIGURE 3. The illustration above shows the test setup for measuring the shear bond strengths of specimens, the system from the front (on left) and the drawing from side (on right). 


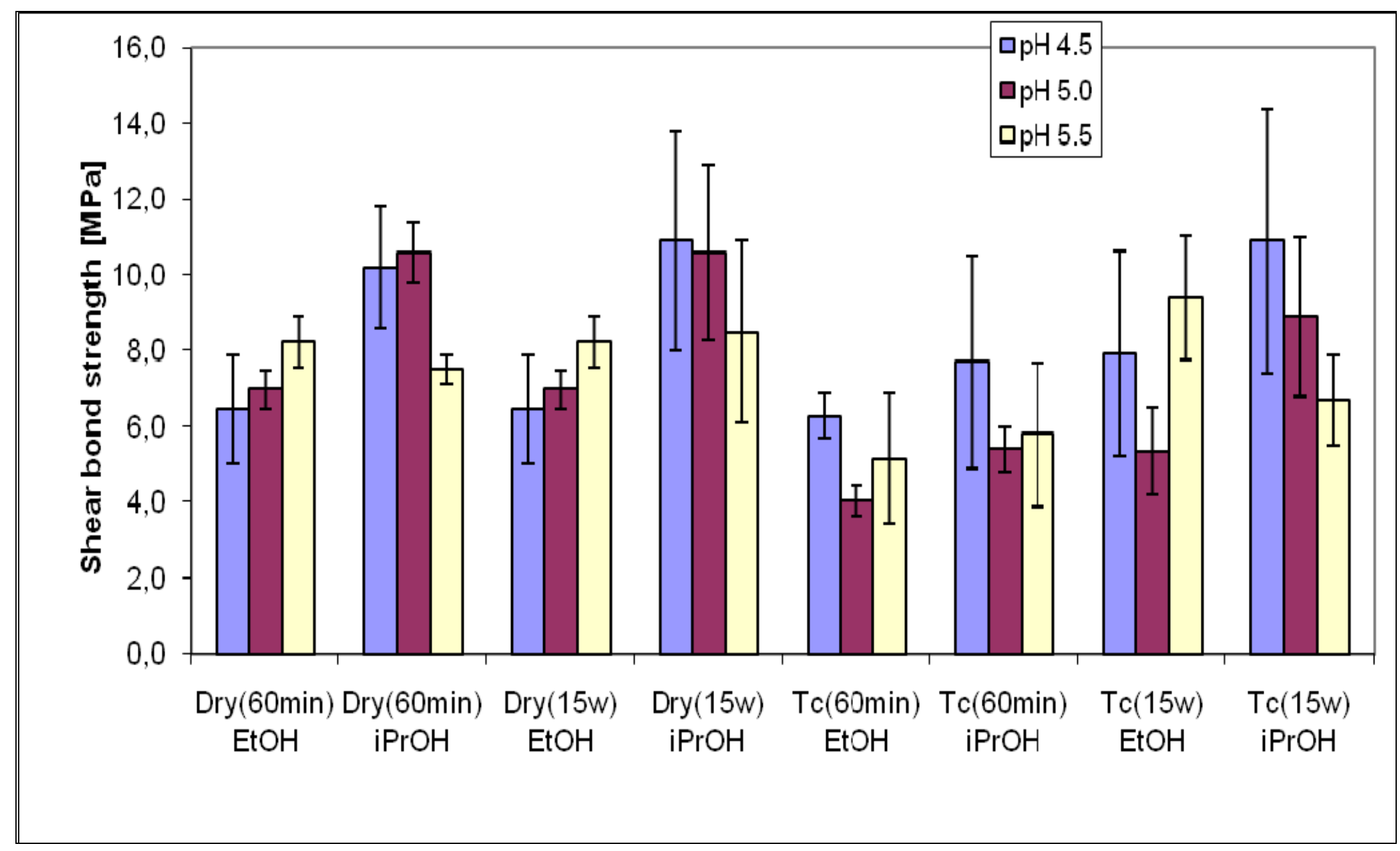

FIGURE 4. The shear bond strength of the specimens prepared using either 'fresh' silane solution, i.e. the hydrolysis reaction time for MPS silane in ethanol $(\mathrm{EtOH})$ and iso-propanol $(\mathrm{i}-\mathrm{PrOH})$ solutions was $1 \mathrm{~h}$, or silane solution after 15 weeks $(\mathrm{w})$ hydrolysis reaction time. The tests were performed either after dry storage conditions ('Dry') or after subjecting to thermo-cycling ('Tc'). The color of bars indicates the pH value of silane solution. 


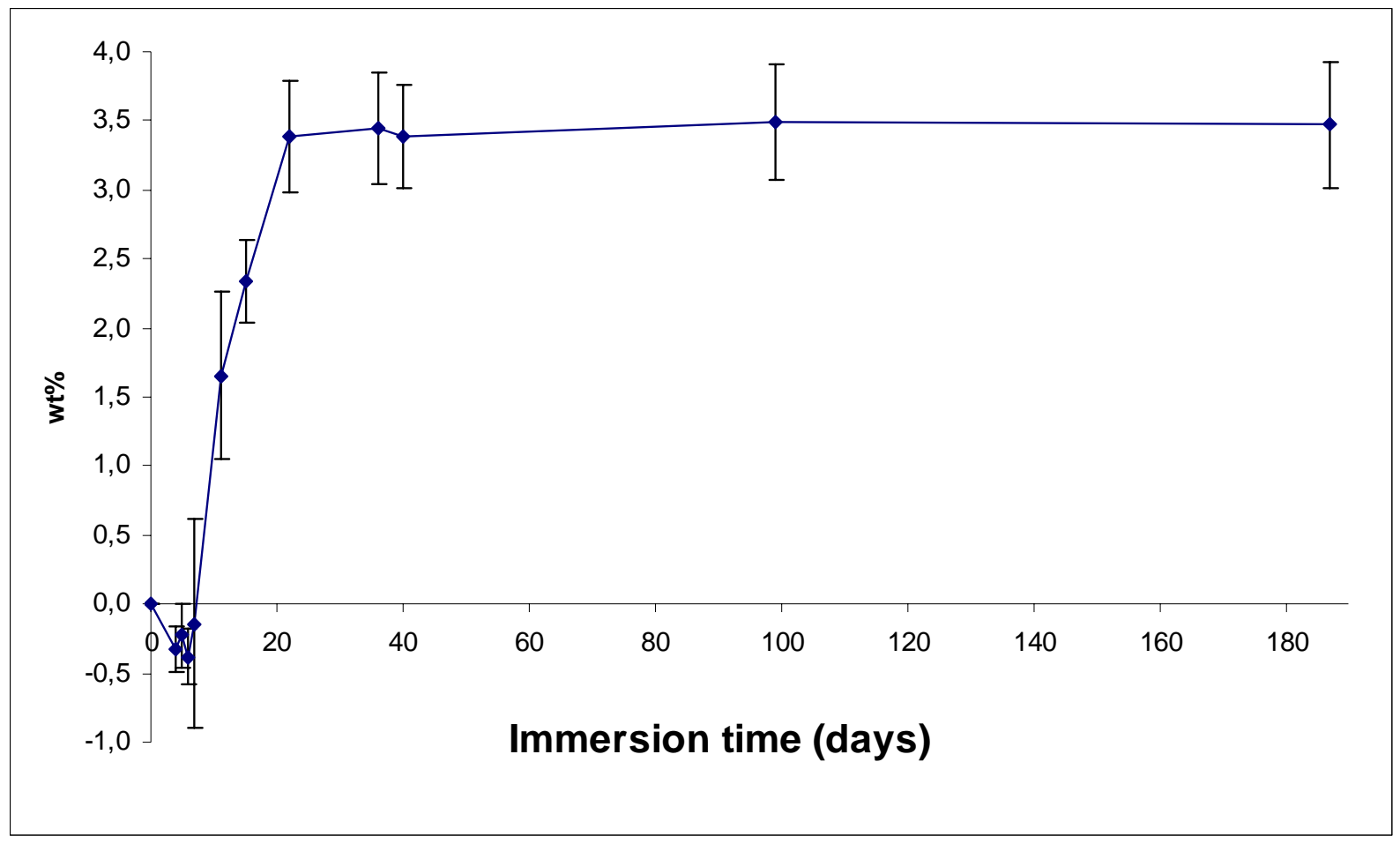

FIGURE 5. The curve demonstrates the weight increase during the water sorption test for the experimental dental resin. 
Table 1. Materials used in the study.

\begin{tabular}{|c|c|c|c|c|}
\hline Brand & Abbr. & Manufacturer & $\begin{array}{c}\text { Lot } \\
\text { number }\end{array}$ & Type of material \\
\hline Bisphenol-A-glycidyldimethacrylate & BisGMA & $\begin{array}{l}\text { Röhm, } \\
\text { Germany }\end{array}$ & T0109/1 & \multirow{4}{*}{$\begin{array}{r}\text { Experimental } \\
\text { dental resin }\end{array}$} \\
\hline Methyl methacrylate & MMA & $\begin{array}{c}\text { Fluka, } \\
\text { Switzerland }\end{array}$ & 1119540 & \\
\hline Camphorquinone & CQ & $\begin{array}{c}\text { Fluka, } \\
\text { Switzerland }\end{array}$ & $448343 / 1$ & \\
\hline $\begin{array}{l}\text { N,N-Dimethylaminoethyl } \\
\text { methacrylate }\end{array}$ & DMAEMA & $\begin{array}{l}\text { Aldrich, } \\
\text { Germany }\end{array}$ & $00628 \mathrm{MU}$ & \\
\hline Ethanol $(99.5 \%)^{1}$ & EtOH & $\begin{array}{l}\text { Primalco, } \\
\text { Finland }\end{array}$ & 160306 & \multirow{4}{*}{$\begin{array}{r}\text { Experimental } \\
\text { silane } \\
\text { solutions } \\
\text { (types } 1-4)\end{array}$} \\
\hline 2-propanol (iso-propanol) ${ }^{2}$ & $i-\mathrm{PrOH}$ & Rathburn, UK & 2J06MA & \\
\hline Acetic acid (glacial, 99.8\%) & $\mathrm{AcOH}$ & $\begin{array}{l}\text { Merck, } \\
\text { Germany }\end{array}$ & $\begin{array}{c}\text { K22810463 } \\
\quad 610\end{array}$ & \\
\hline $\begin{array}{l}\text { Methacryloxypropyltrimethoxysilane } \\
(98 \%)\end{array}$ & MPS & $\begin{array}{l}\text { Aldrich, } \\
\text { Germany }\end{array}$ & $\begin{array}{l}\text { S01603- } \\
022\end{array}$ & \\
\hline Titanium plate (grade 2 ) & $\mathrm{Ti}$ & $\begin{array}{l}\text { Permascand, } \\
\text { Sweden }\end{array}$ & $\begin{array}{l}\text { AS TM } \\
\text { B26589 }\end{array}$ & Metal substrate \\
\hline
\end{tabular}

\footnotetext{
${ }^{1}$ In silane solutions of types 1 and 3, the solvent employed was a mixture of ethanol and water.

${ }^{2}$ In silane solutions of types 2 and 4, the solvent employed was a mixture of 2-propanol and water.
} 
Table 2. Classification of test groups for measuring the shear bond strengths.

\begin{tabular}{|c|c|c|c|c|c|c|c|}
\hline Group & $\mathbf{N}$ & $\begin{array}{c}\text { Silane } \\
\text { solution }\end{array}$ & $\begin{array}{l}\text { Solvent in the } \\
\text { silane solution }\end{array}$ & & pH & & $\begin{array}{c}\text { Time of } \\
\text { hydrolysis }\end{array}$ \\
\hline $\operatorname{Dry}^{1}(60 \mathrm{~min})$ & 6 & Type 1 & $\mathrm{EtOH} / \mathrm{H}_{2} \mathrm{O}$ & 4.5 & 5.0 & 5.5 & $60 \mathrm{~min}$ \\
\hline $\mathrm{Tc}^{2}(60 \mathrm{~min})$ & 6 & Type 1 & $\mathrm{EtOH} / \mathrm{H}_{2} \mathrm{O}$ & 4.5 & 5.0 & 5.5 & $60 \mathrm{~min}$ \\
\hline Dry (60 min) & 6 & Type 2 & $i-\mathrm{PrOH} / \mathrm{H}_{2} \mathrm{O}$ & 4.5 & 5.0 & 5.5 & $60 \mathrm{~min}$ \\
\hline $\mathrm{Tc}(60 \mathrm{~min})$ & 6 & Type 2 & $i-\mathrm{PrOH} / \mathrm{H}_{2} \mathrm{O}$ & 4.5 & 5.0 & 5.5 & $60 \mathrm{~min}$ \\
\hline Dry $(15 \mathrm{w})$ & 6 & Type 3 & $\mathrm{EtOH} / \mathrm{H}_{2} \mathrm{O}$ & 4.5 & 5.0 & 5.5 & $15 \mathrm{w}$ \\
\hline $\mathrm{Tc}(15 \mathrm{w})$ & 6 & Type 3 & $\mathrm{EtOH} / \mathrm{H}_{2} \mathrm{O}$ & 4.5 & 5.0 & 5.5 & $15 \mathrm{w}$ \\
\hline Dry (15 w) & 6 & Type 4 & $i-\mathrm{PrOH} / \mathrm{H}_{2} \mathrm{O}$ & 4.5 & 5.0 & 5.5 & $15 \mathrm{w}$ \\
\hline $\mathrm{Tc}(15 \mathrm{w})$ & 6 & Type 4 & $i-\mathrm{PrOH} / \mathrm{H}_{2} \mathrm{O}$ & 4.5 & 5.0 & 5.5 & $15 \mathrm{w}$ \\
\hline
\end{tabular}

${ }^{1}$ Dry: The shear bond strengths were measured immediately after the preparation of specimens, i.e. in dry conditions.

${ }^{2} \mathrm{Tc}$ : The shear bond strengths were measured after the subjecting specimens to thermal stress, i.e. after thermo-cycling. 